\title{
ПОЛЕВЫЕ ИССЛЕДОВАНИЯ МНОГОСЛОЙНОЙ СТОЯНКИ РАХАТ в 2018 г.
}

\author{
(C2018 г. Е.А. Джасыбаев, Д.В. Ожерельев, Т.Б. Мамиров
}

В статье изложены результаты полевых исследований 2018 г., проводившихся на многослойной стоянке Рахат. Данный объект является уникальным для изучения древнего периода Жетысу и близлежащих регионов, так как памятники с сохранившимся культурным слоем эпохи палеолита в регионе единичны. Проведенные международной командой работы позволили проследить мощность культуросодержащих отложений и показали наличие восьми культурных слоев сохранившимися in situ. Памятник имеет большой научный потенциал и перспективу исследований. Археологические материалы показывают, что человек впервые появился здесь в конце среднего - начале верхнего палеолита и в дальнейшем посещал это место неоднократно на протяжении нескольких тысяч лет. Несмотря на незначительную каменную коллекцию, становится ясно, что инвентарь из разных слоев делает возможным проследить изменения археологической культуры каменного века второй половины позднего плейстоцена на территории северных предгорий Тянь-Шаня. Это, в свою очередь, позволяет с максимальной долей достоверности проводить исследование погребенных материалов с возможностью создания локальных либо более масштабных периодизационных схем появления и развития верхнепалеолитических индустрий (культур, комплексов) Азии. Стоянка Рахат является вторым стратифицированным памятником позднего палеолита всего Юго-Восточного Казахстана, на которой начаты и будут продолжены комплексные научные исследования.

Ключевые слова: археология, каменный век, палеолит, стратиграфия, каменные орудия, культура, индустрия, каменное расщепление, каменное сырье, раскопки

В июне 2018 г. совместной исследовательской группой Государственного историко-культурного музея-заповедника «Иссык» и Института археологии РАН проводились разведочные раскопки стоянки Рахат. Памятник был обнаружен в 2006 г. Тогда же была получена первая информация по стратиграфии стоянки, собрана значительная коллекция находок [Мамиров, 2007; Ожерельев, 2007; Артюхова, 2010;].

Стоянка Рахат расположена в 8 км к ЗЮЗ от г. Есик (Енбекши- казахский p-н, Алматинская обл., $\left.\mathrm{N} 43^{\circ} 21,481^{\prime}, \mathrm{E} 077^{\circ} 22,679^{\prime}\right)$. Абсолютная высота памятника 952 м над у.м. Памятник находится на правом берегу одноименной реки при выходе ее из ущелья в предгорную зону (рис. 1). Река Рахат является предгорной по типу рекой, имеющей родниковое питание. При выходе из гор ущелье реки расширяется, и река распадается на несколько русел. Одно из этих русел проходит прямо возле правого берега, частично подмывая его высокий борт. Геоморфологическая пози- 
ция стоянки связана с лессовидными суглинками, покрывающими на данном участке террасовидные уступы хребта Иле Алатау. Эта форма рельефа, присущая предгорьям хребта, получила наименование «прилавки» [Додонов, 2002; Кусаинов, 2017]. «Прилавки» формировались в плейстоценовое время, являются характерной формой рельефа Иле Алатау. «Прилавки» включают два террасовидных уступа (ступени) - верхний (1200-1700 м над у.м.) и нижний (900-1200 м над у.м.). Согласно этому расчленению стоянка Рахат связана с нижними «прилавками», в месте, где они непосредственно переходят в верхний уступ «прилавков».

Обнаружение стоянки фактически стало счастливой случайностью. Долгое время здесь добывались суглинки, следствием чего стало частичное обнажение лессовидных отложений правого берега р. Рахат. В настоящее время памятник имеет вид карьера по добыче глин с высокой вертикальной стеной, достигающей 13 м. В разные годы на памятнике производились научные изыскания, заключавшиеся в сборе подъемного материала, небольших зачистках отдельных участков в обнажении разреза (сборе, выявленного в ходе зачисток археологического материала, отборе образцов на анализы) [Mамиров, 2007; Бексеитов и др., 2016]. Однако, до сих пор отсутствовало конкретное представление о полной стратиграфии памятника и его датировке. Объект историко-культурного наследия с каждым годом подвергался разрушению в результате продолжения работ по разработке глины местным населением, а также при естественном разрушении стен карьера. Исходя из этого, было принято решение по археологическому обследованию памятника путем закладки траншеи и шурфа на одном из участков обнажения.

В результате этих работ была исследована толща лессовидных су-

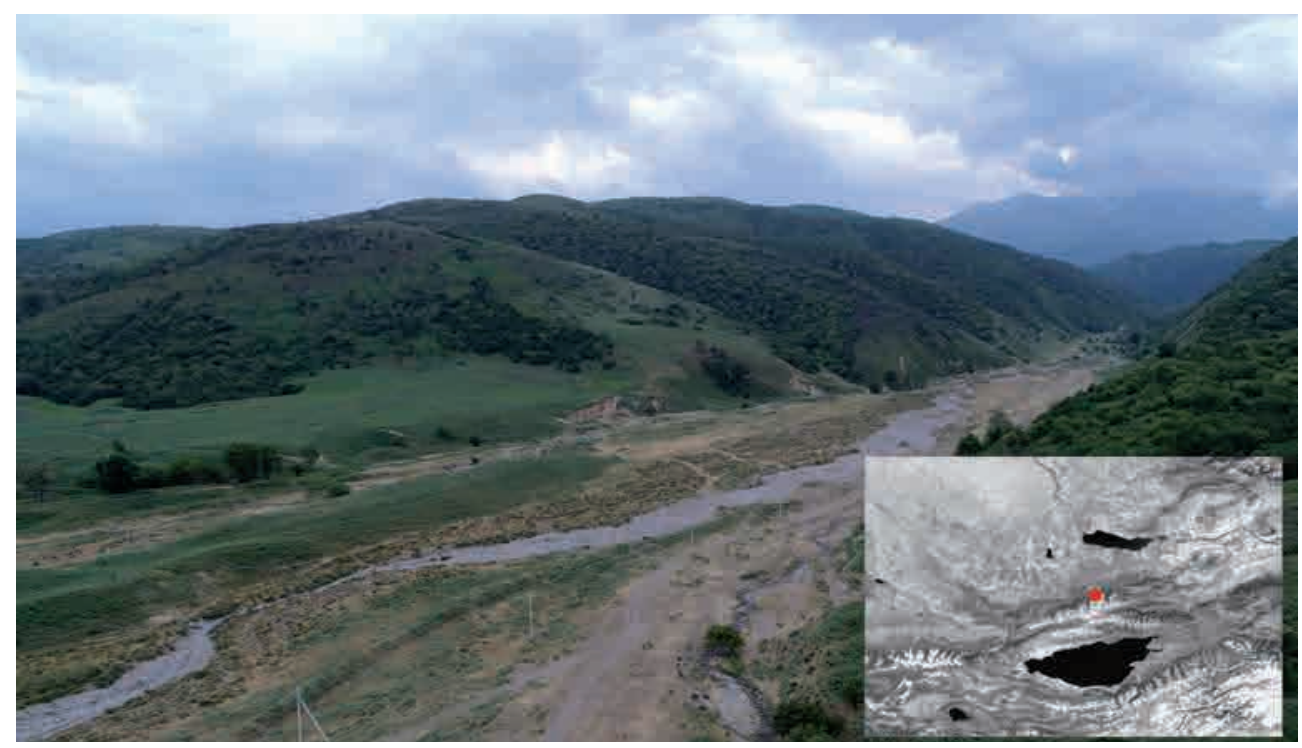

Рис. 1. Вид на долину р. Рахат в месте расположения одноименной стоянки. Фото авторов

Fig. 1. View of the valley of river Rahat at the location of the same name site. Author's photo 
глинков мощностью 13 м. При помощи траншеи и зачистки борта памятник изучался на глубину от 0 до 11,3 м. Начиная с глубины 11,3 м, что соответствует современной поверхности дна карьера, был заложен шурф размерами $1 \times 2$ м. Глубина шурфа составила 1,7 м. Дальнейшие работы в шурфе были приостановлены на уровне слоя речного аллювия (рис. 2). Таким образом, была стратиграфически изучена вся культуросодержащая толща отложений памятника, включающая 13 м. В кратком виде стратиграфия стоянки Рахат может быть описана следующим образом: 1 - современный дерновый слой (0/0,1 м); 2 - современная почва темнокоричневого цвета $(-0,1 /-1,9$ м); 3 - суглинок коричневатый, плотный, в верхней части более коричневый, поскольку прокрашен современной почвой, к нижней части светлеет, приобретая постепенно более серый цвет $(-1,9 /-4,05)$. Контакт с нижележащим слоем нечеткий; 4 - суглинок серовато-коричневый, значительно опесчаненный, пористый $(-4,05 /-7,8$ м). На глубине -6,0/-7,5 м более серый, включает культурные слои 1-3. На глубинах -7,5/-7,8 м наблюдается постепенный переход к нижележащему слою; 5 - суглинок коричневый, неопесчаненный, плотный (-7,8/9,4 м). Нижний контакт нечеткий; 6 - суглинок серовато-коричневый, значительно опесчаненный, пористый (-9,4/-10,4 м). Содержит находки культурного слоя 4. Нижний контакт постепенный; 7 - суглинок коричневатый, слегка опесчаненный, с включением мелкой слабоокатанной гальки (-10,4/-11,80 м). Содержит находки культурных слоев 5-7. Нижний контакт постепенный; 8 - суглинок коричневый, неопесчаненный, более глинистый по сравнению с вышележащим слоем (-11,8/-12,2 м). Количество гальки увеличивается. Содержит культурный слой 8. Нижний контакт нечеткий; 9 - суглинок серовато-коричневый с признаками оглеенности, слегка опесчаненный $(-12,2 /-13,0$ м). Количество гальки увеличивается. Нижний контакт четкий; 10 - галечно-валунные отложения с глинистым заполнителем (с глубины -13,0 м).

При дальнейших раскопках стоянки на значительных площадях стратиграфия и количество культурных слоев могут быть уточнены и скорректированы в сторону большей детализации. Но уже на данный момент понятно, что в изученной толще выделяется современная почва, а также два горизонта, которые предварительно можно охарактеризовать как погребенные позднеплейстоценовые почвы. Это два слоя сероватокоричневых суглинков (глубины - -6,0/-7,5 м; -9,4/-10,4 м), содержащих культурные слои 1-4. Так как исследовался борт карьера, который имеет неровную форму, площадь вскрытия всех культурных слоев различная. Максимальная площадь - до 2,5 кв.м.

Культурные слои представляют собой погребенные уровни обитания с четкой вертикальной локализацией либо незначительным рассеиванием находок по высоте. За исключением слоя 8, каждый слой содержит угли. В слое 1 были обнаружены прокалы и углистые пятна. В слое 4 был обнаружен очаг. Точную форму очага определить пока невозможно, так как значительная его часть уходит в борт восточной стенки. Но, по всей видимости, он имеет подокруглые очертания, с центральной, более мощной частью и с периферийными участками. В разрезе очаг близок к линзовидной 


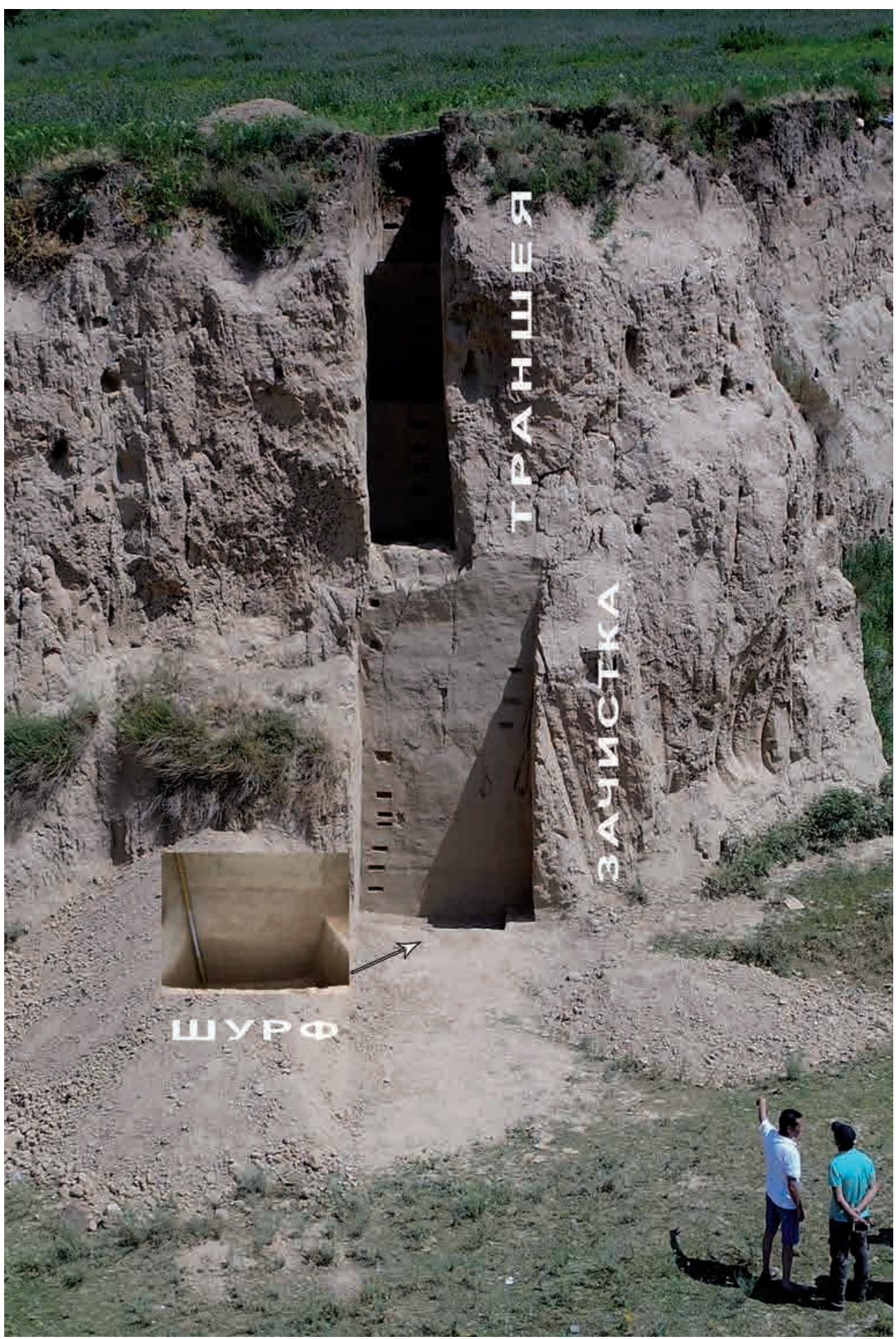

Рис. 2. Раскопочные работы на стоянке Рахат в 2018 г. На фотографии отмечены ступенчатая траншея, зачистка борта обнажения и шурф

Fig. 2. Excavation work at the Rakhat site in 2018. The photo shows a stepped trench, stripping of the exposure and pit 
Джасыбаев Е.А., Ожерельев Д.В., Мамиров Т.Б. Полевые исследования многослойной стоянки...

форме. Максимальная его мощность достигала 15 см в центральной части. Заполнение очага - угли, углистая масса черного и темно-серого цветов. В очаге встречаются отдельные каменные находки (пренуклеус, отщепы) (рис. 3).

Всего во всех слоях была обнаружена 121 находка, включая также каменные изделия, полученные при промывке грунта из культурных слоев. Орудий немного, всего 3 ед.: скребок, оформленный на истощенном микронуклеусе, двойной боковой скребок и фрагмент первичной пластины с ретушью. Первичное расщепление представлено двумя пренуклеусами, нуклевидным обломком, отщепами (27 экз.), пластинчатым отщепом, пластиной, пластинкой, микропластиной, различного рода обломками (35 экз.), техническим сколом т.н. «таблеткой» и многочисленными чешуйками (рис. 4, 1-7). Исходя из категориальной предста- вительности инвентаря, на стоянке проводился полный цикл расщепления сырья и изготовления орудий. В трех слоях были получены частичные сборки между собой каменных изделий (ремонтаж).

В качестве сырья использовался широкий спектр горных пород и минералов. Подавляющее большинство изделий выполнено на местном сырье, происходящем из галечника p. Рахат. Это порфириты, диориты, риолиты различных цветов и оттенков с низким изотропным составом. Использовалось также более пластичное сырье - эффузивы серого цвета, близкие по качеству к песчаникам, и зеленоватого цвета порода, напоминающая кремень. Это сырье, видимо, происходит из русла реки, но встречается оно здесь крайне редко. Кроме того, в коллекции имеются предметы из кремня различных цветов, которые явно приносились на стоянку из других мест.

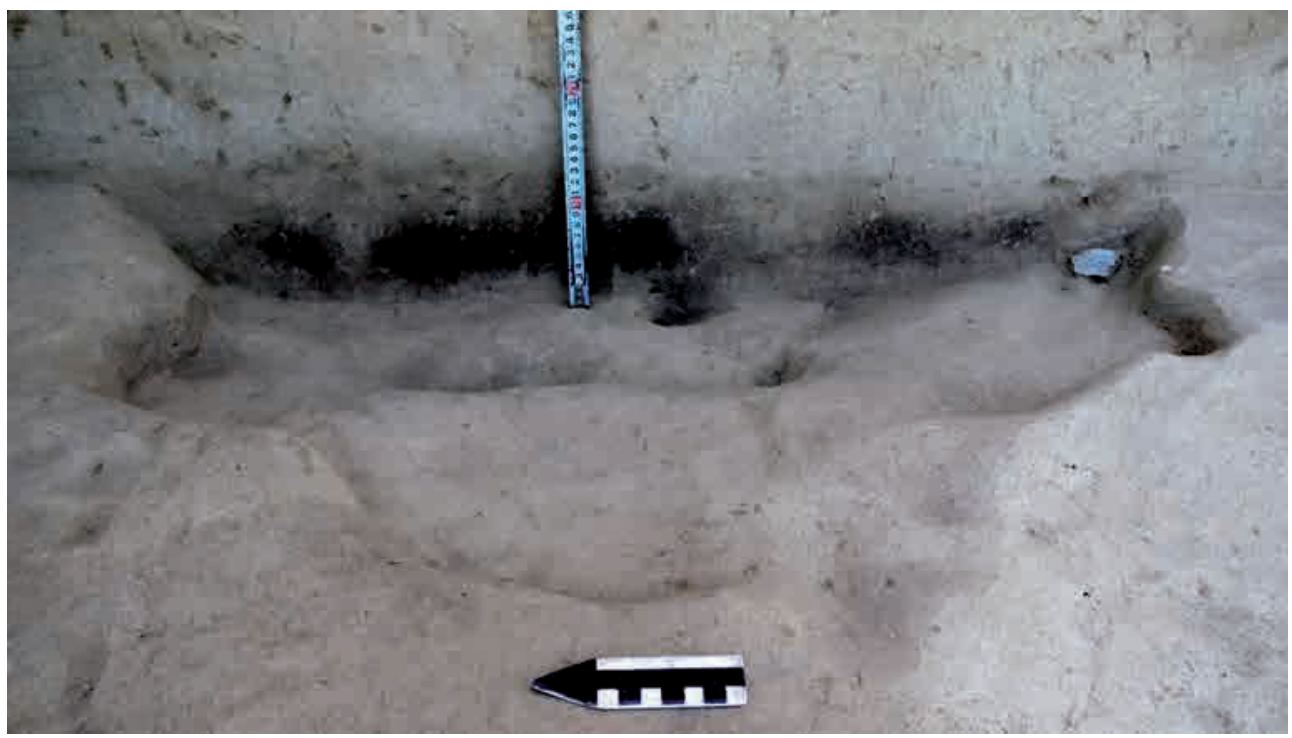

Рис. 3. Очаг из слоя 4 и его разрез после полной расчистки. Значительная часть очага уходит в восточную стенку

Fig. 3. The hearth from layer 4 and it's incision after complete stripping. A significant part of the hearth goes into the eastern wall 

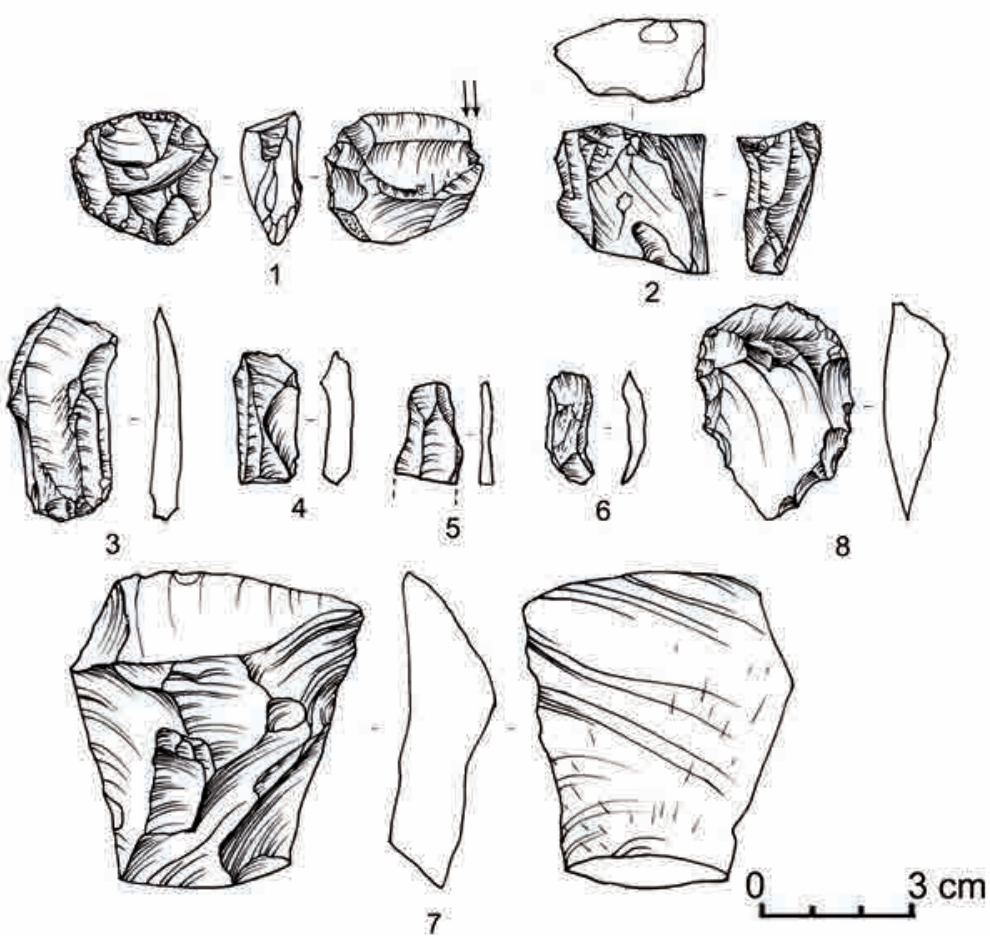

Рис. 4. Каменные изделия стоянки Рахат: 1 -микронуклеус-скребок (слой 5); 2 - нуклевидный обломок (слой 2); 3 - пластина (слой 2); 4 - пластинка (слой 3); 5 -обломок пластинки (слой 1); 6-микропластина (слой 2); 7 - отмел (слой 7); 8 - скребок (слой 5)

Fig. 4. Stone products of the Rakhat site: 1 -micronucleus-scraper (layer 5); 2 -nuclide debris (layer 2); 3 -blade (layer 2); 4 -blade (layer 3); 5 - a fragment of a blade (layer 1); 6-microblade (layer 2); 7 -flake (layer 7); 8 -scraper (layer 5)

По предварительным данным, стратиграфии, характеру культурных слоев, облику каменной индустрии памятник может быть сопоставлен со стоянкой Майбулак (Жамбылский p-н, Алматинская обл.), расположенной в 44 км к западу от города Алматы, возраст которой составляет порядка 40-25 тысяч лет [Ожерельев, 2005; 2012; Таймагамбетов, Ожерельев, 2008; 2009; Feng et al., 2011; Fitzsimmons et al., 2017].

Памятник имеет большой научный потенциал и перспективу исследований. Значение его, в частности, заключается в том, что он содержит минимум два горизонта, которые можно характеризовать как погребенные плейстоценовые почвы. Это, в свою очередь, дает возможность проводить подробные палеогеографические исследования. В почвах содержатся культурные слои превосходной сохранности in situ c различными объектами, характерными для верхнепалеолитических стоянок. Основные периоды ее обживания увязываются с благоприятными климатическими условиями межледниковий. Северные предгорья Иле Алатау и во времена последних оледенений представляли собой природно-климатические оазисы, притягивавшие людей верхнего палеолита богатством растительного, животного мира и обильными источ- 
никами воды. Археологические материалы стоянки указывают на то, что человек впервые появился здесь в конце среднего - начале верхнего палеолита и в дальнейшем посещал это место неоднократно на протяжении нескольких тысяч лет. Несмотря на незначительную каменную коллекцию, становится ясно, что инвентарь из разных слоев делает возможным проследить изменения археологической культуры каменного века второй половины позднего плейстоцена северных предгорий Тянь-Шаня. Это в свою очередь позволяет с максимальной долей достоверности проводить исследование погребенных материалов с возможностью создания локальных либо более масштабных периодизационных схем появления и развития верхнепалеолитических индустрий (культур, комплексов) Азии. На стоянках Рахат и Майбулак предварительно устанавливаются с одной стороны тенденции развития каменной индустрии ранних этапов верхнего палеолита, свойственных другим регионам Европы и Азии. В то же время выявляются особенные признаки, которые могут в какой-то мере помочь понять культурные и поведенческие принципы развития верхнего палеолита Центральной Азии. Таким образом, стоянка Рахат является вторым стратифицированным памятником позднего палеолита всего Юго-Восточного Казахстана, на которой начаты и будут продолжены комплексные научные исследования.

\section{ЛИТЕРАТУРА}

1. Артюхова O.A. Проблемы позднего палеолита Казахстана // Известия НАН РК. Сер. обществ. наук. 2010. № 1. С. 3-8.

2. Бексеитов Г.Т., Оспанов Е.Б. Исследования на позднепалеолитической стоянке Рахат в Семиречье // Новые методы исследования в археологии: матер. междунар. научн.-практ. конф. Алматы: Қазақ университеті, 2016. С. 163-167.

3. Додонов А.Е. Четвертичный период Средней Азии. М.: ГЕОС, 2002. 250 с.

4. Кусаинов C.A. Четвертичная геология (основы и методы исследования). Алматы: Қазақ университеті, 2017. 330 с.

5. Мамиров Т.Б. Новые материалы по палеолиту Юго-Восточного Казахстана (по данным разведочных работ 2006 года) // Археология, этнология, палеоэкология Северной Евразии и сопредельных территорий: матер. 47 рег. археол.-этногр. конф. студентов и молодых ученых Сибири и Дальнего Востока (г. Новосибирск, 3-4 апреля 2007 г.). Новосибирск, 2007. С. 27-28.

6. Ожерельев Д.В. Археологические работы экспедиции КазНУ им. аль-Фараби по изучению памятников каменного века в Казахстане в 2004 году // Вестник КазНУ. Сер. историч. 2005 № 3 (38). С. 100-111.

7. Ожерельев Д.В. Открытия палеолита в предгорьях Заилийского Алатау (Юговосточный Казахстан) // Археология, этнология, палеоэкология Северной Евразии и сопредельных территорий: матер. 47 рег. археол.-этногр. конф. студентов и молодых ученых Сибири и Дальнего Востока (г. Новосибирск, 3-4 апреля 2007 г.). Новосибирск, 2007. C. 33-35.

8. Ожерельев Д.В. Новейшие открытия палеолитических памятников в Юговосточном Казахстане // КСИА. 2012. Вып. 227. С. 182-191.

9. Таймагамбетов Ж.К., Ожерельев Д.В. Позднепалеолитические памятники Казахстана. Алматы: Қазақ университеті, 2009. 256 с.

10. Таймагамбетов Ж.К., Ожерельев Д.В. Изучение стратифицированной стоянки Майбулак в Жетысу (Юго-восточный Казахстан) в 2004-2007 гг. // Мирас. 2008. № 1. C. 70-85.

11. Fitzsimmons K.E., Iovita R., Sprafke T., Glantz M., Talamo S., Horton K., Beeton T., Alipova S., Bekseitov G., Ospanov E., Deom J.-M., Sala R., Taimagambetov J., 2017. A chronological framework connecting the early Upper Palaeolithic across the Central Asian piedmont. Journal of Human evolution. 113. 107-126. 
12. Feng Z.-D., Ran M, Yang Q.L., Zhai X.W., Wang W., Zhang X.S., Huang C.Q., 2011. Stratigraphies and chronologies of late Quaternary loessepaleosol sequences in the core area of the central Asian arid zone. Quatern. Int. 240. 156-166.

Сведения об авторах:

Джасыбаев Ермек Аманжолович - магистр истории, заместитель директора, Государственный историко-культурный заповедник-музей «Иссык» (г. Есик, Казахстан); ormik80@mail.ru

Ожерельев Дмитрий Викторович - кандидат исторических наук, научный сотрудник Отдела археологии каменного века, Институт археологии РАН (г. Москва, Россия); dim_as_oj@mail.ru

Мамиров Талгат Базарбаевич - кандидат исторических наук, директор, Филиал Института археологии им. А.Х. Маргулана в г. Астане (г. Астана, Казахстан); tmamirov@mail.ru

\section{8 ЖЫЛҒЫ КӨПҚАБАТТЫ РАХАТ ТҰРАҒЫНДАҒЫ ДАЛАЛЫК ЗЕРТТЕУЛЕР}

\section{Е.А. Джасыбаев, Д.В. Ожерельев, Т.Б. Мамиров}

Мақалада 2018 жылы көпқабатты Рахат тұрағында жүргізілген далалық зерттеулер туралы мәліметтер келтіріледі. Бұл нысан Жетісу және жақын орналасқан өңірлердің ежелгі кезеңін зерттеу үшін бірегей болып табылады, себебі аймақта палеолит дәуірінің мәдени қабаты сақталған ескерткіштері өте сирек. Халықаралық жасақпен жүргізілген жұмыстар орман шөгінділерінің орналасу қуатын бақылауға мүмкіндік берді, сонымен қатар жәдігерлері бүлінбеген сегіз мәдени қабаттың болғанын көрсетті. Ескерткіш үлкен ғылыми әлеуетке және зерттеу болашағына ие. Тұрақтың археологиялық мәліметтері бойынша мұнда жоғарғы палеолиттің басы мен орта палеолиттің соңында алғаш рет адамның пайда болғанын, кейіннен бұл орынға бірнеше мың жыл бойы үздіксіз келіп отырғандығын көрсетеді. Аздаған тас жинақтамасына қарамастан, әртүрлі қабаттардан табылған құрал-саймандар Тянь-Шань тауының солтүстік тоғандық аумағында кейінгі плейстоценнің екінші жартысындағы тас дәуірінің археологиялық мәдениетінің өзгеруін байқауға мүмкіндік береді. Бұл өз кезегінде, жерлеу ғұрпын барынша үлкен үлеспен зерттеуге, Азияның жоғарғы палеолит өнеркәсібінің (мәдениеттердің, кешендердің) пайда болуы мен дамуының жергілікті әлде неғұрлым ауқымды кезеңделу үлгілерін жасауға жағдай туғызады. Рахат тұрағы - кешенді ғылыми зерттеу басталған және одан әрі жалғастырылатын, Қазақстанның бүкіл оңтүстік-шығыс аумағы бойынша кейінгі палеолит дәуіріне тиесілі екінші мәдени қабатталған ескерткіш болып саналады.

Түйін сөздер: археология, тас ғасыры, палеолит, стратиграфия, тас құралдары, мәдениет, өнеркәсіп, тас ыдырату, тас шикізаты, қазбалар

\section{FIELD RESEARCHES OF THE MULTILAYER MONUMENT «RAKHAT» IN 2018}

\section{E.A. Jasybayev, D.V. Ozherelyev, T.B. Mamirov}

The article contains information about the field research conducted on the multilayer monument «Rakhat» in 2018. This object is unique for studying the ancient period of Jetysu and nearby regions, since the monuments with the preserved cultural layer of the Paleolithic epoch in the region are single. The work carried out by the international team made it possible to trace the thickness of the loess deposits and showed the presence of eight cultural layers, with preserved in situ artifacts. The monument has a great scientific potential and perspective of research. Archaeological materials of the monument indicate that the man first appeared here at the end of the Middle Paleolithic - at the beginning of the Upper Paleolithic and subsequently visited this place repeatedly for several thousand years. Despite the small collection of the stone artifacts, it becomes clear that the inventory from different layers makes it possible to trace the changes in the archaeological culture of the Stone Age of the second 
half of the late Pleistocene in the northern foothills of the Tien Shan. This, in turn, allows the study of buried materials with a maximum degree of certainty, with the possibility of creating local or more large-scale periodization schemes for the appearance and development of the Upper Paleolithic industries (cultures, complexes) in Asia. The monument «Rakhat» is the second stratified monument of the late Paleolithic of the entire Southeast Kazakhstan, where comprehensive scientific research has been and will continue.

Keywords: archaeology, the Stone Age, Paleolith, stratigraphy, stone tools, culture, industry, stone cleavage, stone raw materials, excavations

\section{REFERENCES}

1. Artjuhova, O. A. 2010. In Izvestija NAN RK (Proceedings of the National Academy of Sciences of the Republic of Kazakhstan), 1, 3-8 (in Russian).

2. Bekseitov, G. T., Ospanov, E. B. 2016. In Novye metody issledovanija v arheologii (New research methods in archaeology). Almaty: "Qazaq universiteti” Publ., 163-167. (in Russian).

3. Dodonov, A. E. 2002. Chetvertichnyj period Srednej Azii (Quaternary period of Central Asia). Moscow: "GEOS" Publ. (in Russian).

4. Kusainov, S. A. 2017. Chetvertichnaja geologija (osnovy i metody issledovanija) (Quaternary geology (fundamentals and methods of research)). Almaty: "Qazaq universiteti" Publ. (in Russian).

5. Mamirov, T. B. 2007. In Arheologija, jetnologija, paleojekologija Severnoj Evrazii $i$ sopredel'nyh territorij (Archeology, ethnology, paleoecology of Northern Eurasia and adjacent territories). Novosibirsk, 27-28 (in Russian).

6. Ozherelyev, D. V. 2005 In Vestnik KazNU. Serija istoricheskaja (Bulletin of the Kazakh National University. Historical series), 3 (38), 100-111 (in Russian).

7. Ozherelyev, D. V. 2007. In Arheologija, jetnologija, paleojekologija Severnoj Evrazii i sopredel'nyh territorij (In Archeology, ethnology, paleoecology of Northern Eurasia and adjacent territories). Novosibirsk, 33-35. (in Russian).

8. Ozherelyev, D. V. 2012. In Kratkie soobshhenija Instituta arheologii (In Brief reports of the Institute of Archeology), 227, 182-191 (in Russian).

9. Tajmagambetov, J. K., Ozherelyev, D. V. 2009. Pozdnepaleoliticheskie pamjatniki Kazahstana (Late Paleolithic monuments of Kazakhstan). Almaty: "Qazaq universiteti” Publ. (in Russian).

10. Tajmagambetov, J., Ozherelyev, D. V. 2008. In Miras, 1, 70-85 (in Russian).

11. Fitzsimmons, K. E., Iovita, R., Sprafke, T., Glantz, M., Talamo, S., Horton, K., Beeton, T., Alipova, S., Bekseitov, G., Ospanov, E., Deom, J.-M., Sala, R., Taimagambetov, J., 2017. In Journal of Human evolution, 113, 107-126.

12. Feng Z.-D., Ran M, Yang Q.L., Zhai X.W., Wang W., Zhang X.S., Huang C.Q., 2011. In Quatern. Int., 240, 156-166.

\section{About the Authors:}

Jasybayev Ermek A. Master of History, Deputy Director, State Historical and Cultural Reserve-Museum “Issyk” (Esik, Kazakhstan.); ormik80@mail.ru

Ozherelyev Dmitry V. Candidate of Historical Sciences, researcher of the Department of Archeology of the Stone Age, Institute of Archeology Russian Academy of Sciences (Moscow, Russia); dim_as_oj@mail.ru

Mamirov Talgat $\overline{\mathbf{B}}$. Candidate of Historical Sciences, Director, Branch of the A.Kh. Margulan Archeology Institute in Astana (Astana, Kazakhstan); tmamirov@mail.ru

\footnotetext{
Мүдделер қақтығысы туралы ақпаратты ашу. Авторлар мүдделер қақтығысының жоқтығын мәлімдейді. / Раскрытие информации о конфликте интересов. Авторы заявляют об отсутствии конфликта интересов. / Disclosure of conflict of interest information. The authors claims no conflict of interest.

Мақала туралы ақпарат / Информация о статье / Information about the article. Редакцияға түсті / Поступила в редакцию / Entered the editorial office: 09.09.2018. Рецензенттер мақұлдаған / Одобрено рецензентами / Approved by reviewers: 17.09.2018 Жариялауға қабылданды / Принята к публикации / Accepted for publication: 24.09.2018.
} 